\title{
Integrated mechanics of hybrid electrical air-cushion tracked vehicle for swamp peat
}

\begin{abstract}
This paper presents an integrated mechanics for the design of hybrid electrical air-cushion tracked vehicle. The air-cushion of HETAV is protected with a novel-design air-cushion supporting system which can adjust automatically. A propeller is installed on the vehicle to develop additional thrust for overcoming the dragging motion resistance of the air-cushion system. The mean values of traction for the vehicle with propeller compared with no propeller increased $10.21 \%$ and $6.47 \%$ for the vehicle weight of $2.45 \mathrm{kN}$ and $3.43 \mathrm{kN}$, respectively. Similarly, it was found that the mean values of vehicleôs motion resistance decreases $12.63 \%$ and $25.81 \%$ for the vehicle weight of $2.45 \mathrm{kN}$ and $3.43 \mathrm{kN}$, respectively.
\end{abstract}

Keyword: Air-cushion; Auto-adjusting-supporting system; Hybrid vehicle; Propeller 